\title{
Our Anxious Desires
}

Desires tend to be anxious. A historically important pessimistic tradition supports such a view. The general interpretation of the anxiety thesis depends on the fact that desires are difficult and even impossible to satisfy. Sociologically speaking, desires have been constricted and controlled in many ways in all societies. We also know that some schools of thought and belief have insisted on getting rid of all desires, or at least in minimizing their impact in social life. Also, some writers have promoted the belief to the effect that one should only desire what one already has. Such an extremism is not a viable solution to the problem. We must get along with the core of our desires. In this paper I focus on increasing and non-increasing values as desiderata, negative or zerodesires, and the problem of immodest desires. In my general model of desire and possible worlds such an immodesty requirement can be at least partially corrected: we aim at possible worlds that we can realize, or which are close enough to our own actual world.

\section{Preliminaries}

People tend to get anxious and desires can be problematic in a way that we can call, in a metonymic sense, anxious, too. We could as well talk about unhappy desires but we have a good reason not to do so: happiness and unhappiness are so general terms that their informative usage becomes difficult. It is better to talk about anxiety, or a specific type of unhappiness. Actually, to say what we mean by happiness, or to give a definition, is a hopeless task; yet, we may hope to understand what we mean by anxiety. Anxiety as a folk psychological term is, of course, a multifaceted concept but I suggest that the following account of it is sufficiently clear: Desires are anxious if a person anticipates or experiences personal frustration, that is, her desires will not be satisfied. Such negative anticipation may be rational or irrational; namely, the person may have her reasons or no reasons for his negative anticipation, and if he has good reasons his anticipation is fully rational. In this paper, I deal with rational anticipation of frustration but I do not explicate any theory of the relevant type of rationality. Irrational anticipation means more or less pathological pessimism, depression, or life in bad faith, which are psychological issues I cannot take 
into account here. Of course, anyone may become depressed after experiencing a long string of anxious desires, in which case depression and pessimism start looking rational too. I will, however, concentrate here on the rationally anxious desires.

Not all desires are prone to immediate anxiety. One notable class of such exceptional desires is Sigmund Freud's wishes and wish-fulfilment: I wish I were good in mathematics but I am not. This does not necessarily imply a frustrated desire, for the following reasons. If it is a pure daydream, all is well. We often entertain ourselves with such daydreams. I also may act on the wish; for instance, I buy mathematics books, keep them in my bookcase, and even read them here and there. This makes me happy because now I feel as if I were good in mathematics. In fact, my wish is self-satisfying. When I look at those books for a while I am good in mathematics and a mathematician and this is enough for me in my present state of mind. If I desire or want to be a mathematician, I am prone to disappointment and frustration: I want to be something I can never be. Suppose a cancer patient who knows he will die soon. She wishes to be healthy but in her resignation she knows she is only wishing. In this paper I discuss desires that can be satisfied and the person has good reason to believe this is the case.

I assume that desire tracks satisfaction or that it is an essential truth about desire that it exists only to be satisfied. There are not idle desires. Sometimes we can easily see what this requires. For instance, I want a glass of water and when I get it I say I got what I wanted. Sometimes the situation is more complicated. I want to make more money than before. What do I want? Do I want money, more money, make money, or to make more money? The object of my de dicto desire is not immediately obvious. Certainly I do not want to make money in the sense that making money could satisfy my desire. To make money is just a means for getting money. It is something I need to do. It is possible of course that a person wants the means to reach an object but that always requires its independent explanation. Normally, I want the object of the desire and not what I need to reach the object. To answer the last question, namely, do I want money or more money, I need to spell out the whole situation. In other words, I need a narrative account of the desire. This entails spelling out the desirability conditions that motivate the desire, or answering the question "Why do you want it?" As I see it, the answer may prima facie look quick and simple but after some probing desires entail deep and complex explications, perhaps not in the case of a glass of water but then at least in the case of earning much money - why bother if the needed procedures are laborious, time consuming, and inherently risky? In this way, we say desires track satisfaction 
in such life situations that are in most cases incompletely understood even by the person himself. He aims at objects that he supposes can satisfy his desires and make him content or gratified and in this special sense happy. He aims at such a possible world where he has what he wanted. Notice that sometimes this means acting sometimes not. In many cases we want to act or we need to act but often we only can wait and see how the world turns.

\section{Sources of Frustration and Anxiety}

Some sources of frustration are simple, for instance, the case of returning desire. Some desires are of the type that they extinguish when they are satisfied. Some of those return, some do not. Some desires are not of the returning type in the sense that one cannot extinguish them at all, for instance, one's desire to get attention and admiration from others. In this case, the more you get it the more you want it, and this means not only more of the same but more and more intense attention and admiration. Let me say something about these cases although they are not very interesting as such.

I satisfy my desire and then it vanishes permanently. This is fine, normally no frustration follows. Next, I satisfy my desire that vanishes and returns later. This case may be frustrating or not: In some cases desires are such that I want to get rid of them by satisfying them and, hence, their return is frustrating. There are painful desires, like hunger, or more generally, those that are generated by push and not pull. In some other cases, I welcome back the desire in question and enjoy the idea that I can entertain it again. Sex is a good example, but only if you do not think it is bad and sinful. Frustration seems to be case specific because objects are valued in different ways. In other words, some objects are desired wholeheartedly or without reservation, unlike some others towards which our evaluative attitudes are more complex. It all depends on how we describe and judge the desirability conditions of an object. Figuratively speaking, we may say some of the desirability conditions are clean and some are not. Let me give a simple example: I desire normal sex with my loving wife, which is a clean desire. I desire kinky sex with one of my students, which is a dangerous and in many way dubious object, and therefore it is not a clean one. In this way it seems that desires can be anxious even when they are not frustrated: it is enough that they are not clean. In this case they represent a threat. However, in this case we can say that unclean desires cannot be fulfilled in toto and that is the reason why they are anxious. Such desires contain mutually contradictory elements, which logically entail partial dissatisfiability. I want the object of desire and also want to avoid it; I cannot satisfy this combined desire. You 
act according to the strongest push or pull, which does not bring about full satisfaction. You get one half and miss the other, which entails frustration.

If this is so, we can see why the Buddhists say unhappiness follows from desires and Arthur Schopenhauer condemns the will. Actually, they belong to an age-old pessimistic tradition that condemns desires. It extends from Heraclitus to Simone Weil. ${ }^{1}$ I have no intention to delve into the history of this pessimistic tradition here. I only ask what it tells us that such a tradition exists and then look into some facts about desires that make them likely causes of unhappiness, and more exactly of frustration and anxiety. Other reasons may exist as well, like the Platonic worry that strong and irrational desires come to dominate our mental landscape, or pathos rules instead of nous and logos. This may bring about its own variety of frustration.

Think of two different types of value, increasing and non-increasing, like being alive and money. ${ }^{2}$ The first type of value you may fail to recognize (only) when you possess it. The reason for this seems to be that you cannot increase it: you are alive and it does not make sense to say that you want to increase this good. Of course, figuratively speaking you may say you are only half alive or you desire to live more, but this is not what I have in mind. The hard fact is that you are either dead or alive. If you want to focus on such a value you first need to play with it. You imagine a counterfactual possible world where you are either dead, or close to being dead, and then you may enjoy the feeling and value of being alive. By doing so you satisfy a desire, namely that of realizing the value of being alive - but this desire is bound to be unclean. You are playing with dangerous goods when you remind yourself of the painful fact that this value will not last. You may experience the value of life in full when you think of death but then also the death becomes, perhaps too obvious for comfort. This is another anxious thought.

Concerning health, you certainly value it when you lose it. You value it because now you can imagine an increase of this value, which makes your life feel better. A sick person wants to become better, which is to say she wants the value called health to increase, perhaps to its maximal degree experienced by a healthy person. But to want to be better is in itself an anxious thought because it presupposes that you are not healthy and you hope to be better. In this sense, health unlike life is a semi-increasing, bounded value: it has a maximum that one reaches only rarely. Life is an absolutely non-increasing value so that we

1 P. Wheelwright, Heraclitus. Oxford: Oxford University Press, 1959, pp. 58/\#51, \#52, and 84/\#96; and S. Weil, Gravity and Grace. Trs. E. Crawford and M. von der Ruhr. London: Routledge, 2002.

2 A. Gewirth, Reason and Morality. Chicago: University of Chicago Press, 1978, pp. $240 \mathrm{off}$. 
can say you enjoy life only when you are going to die, really or in your imagination; however, you cannot get better like in the case of health.

Next, let us look at the case of increasing value like money. Above I already hinted at the fact that only an increase of value is desirable. Take any increasing value and it loses its desirability when it remains stable without any immediately imaginable threat to it or a promise of increase. If you have much of the increasing value in question you need to be reminded of its value or otherwise you lose your interest in it. The main point is, however, that no maximum amount of money exists. You always can get and have more. If you have little, or subjectively too little - this also applies to people who possess much of the value in question - then you will enjoy every little bit of increase of this value in your own case; there is no limit to this. I think this is what Simone Weil refers to when she writes that desires are heavy to bear and the only way to get rid of them is to amass the desirabilia until you become too exhausted to carry on. ${ }^{3}$ The desire will vanish when you no longer have the strength to desire what is desirable. This looks like a strange and demanding strategy but at least we can now understand what it is. The problem with increasing value is that you never have it all or enough of it.

Now, increasing value as the foundation of desirabilia forms the prototype of frustrated desire. In other words,? if you desire something that is based on increasing value you are bound to be disappointed. Paradoxically, the reason is that you can never reach to the top where you have all of the value you want. Why is this paradoxical? In the case of non-increasing value, you find yourself in the situation in which the appreciation of the value vanishes, namely, when you have the value to its full degree. In the case of increasing value, you as if (intentionally) aim at such a maximum where the appreciation or enjoyment of this value will then (unintentionally) vanish. Is it not paradoxical that a rich person aims at a situation in which his most valued objects become subjectively worthless? If he realized this, would he become even more frustrated? Of course, in this case such a maximum does not exist. Therefore, in one case we do not appreciate what we have if we do not imagine we lose it; in the other case we aim at the situation where the appreciation of the value would vanish. The conclusion is that, in the case of a non-increasing value, we realize or at least we should realize that we aim at something that has subjective value to us but we cannot enjoy it and yet we aim at it. All of this is bound to be anxious because it is painful. In one case we work hard to get something that does not allow satisfaction; the object duly escapes us. In the other case we reach the maximal object that is now without subjective value. We need to pretend that

3 Weil, 2002, p. 121. 
we lose the value, that is, we deliberately frustrate ourselves and then check our present situation to make sure that we still have it all. In this sense we aim at something that cannot satisfy us, and this is frustrating and anxious.

I said above that both in the case of pseudo-increasing value, which is a value that tends to increase but also has a maximum, and non-increasing value the way to make the corresponding objects look desirable is to focus on their incremental growth, when it takes place factually or counterfactually. Such dialectics makes them subjectively valuable. The normal intuition in such a case seems to be that all of this is painful, in the sense that the person is reminded of life without the value in question. It is painful to rejuvenate your love by reminding yourself what it is to be unloved and unloving. If you are a consistent Epicurean you do not accept such strategy of making yourself conscious of a value by first suffering the pain brought about by the lack of this same value. You should avoid suffering whenever you can. ${ }^{4}$

Now, situations exist where you are able to enjoy the thought or reality of living without a given value. This holds true of any of the value types I reviewed above. Is this perverse or not? Here is an example. Safety is, perhaps, a semiincreasing human value we all appreciate when we have it in a partial sense. It is terrible and terrifying to live without it, that is, to feel the danger. Now, when we feel safe the subjective value of safety tends to vanish and so we remind ourselves about the life of those who must manage without safety and security. This is the standard strategy as I explained above. However, another strategy exists and along with it our thesis of universal frustration gets into trouble. When I am safe I may delight myself by playing dangerous games. If I am in an unsafe environment I may be less inclined to do so, but this is not important here. ${ }^{5}$ The main point is that the loss of the maximal value - I only deal with this case here - can feel positively good or, in other words, it expresses some other, unrelated values that make this loss independently desirable. I understand the importance of safety so that I do what I do in a maximally safe way but what I do is as such dangerous. Alpinists use safety gear but that does not make them safe. It sounds like an oxymoron that I do dangerous things safely. I find it independently enjoyable and delightful to play with danger, if I do it safely; how is this possible? Perhaps in some atavistic manner I intend to prove, by taking risks, that I am unbreakable and invulnerable. In this magical way the idea tends to enhance my personal sense and appreciation of safety.

4 See D. Wolfsdorf, Pleasure in Ancient Greek Philosophy. Cambridge: Cambridge University Press, 2013, Ch. 7 .

5 An interesting study is E. Freedgood, Victorian Writing about Risk. Cambridge: Cambridge University Press, 2000, Chs. 3 and 4. 
I love money but I gamble, which looks like contradiction. Of course people deceive themselves so that they think that risking what is valuable you can get more of it. But this is not the point. The point is that I enjoy gambling as such while it reminds me of the value of money. Winning is so wonderful because of the risk and the risk is subjectively the greater the greater is my love of money. In both cases we correct our perception of value by means of strategies that, in this context, are independently and intrinsically desirable. This removes any traces of frustration from my situation. I do not mean, of course, the frustration that follows from failure and loss, but losses are what you should expect when you gamble. You know all the time that radical frustration is close by but you enjoy exactly that thought. Dialectically, you enjoy a non-increasing value when you play with the idea of losing it; but you enjoy it even more when you independently enjoy the play. Dangerous play is invigorating as such and, moreover, it keeps you focused on the non-increasing goods in your life.

\section{Immodest Desires}

Desire logically entails the lack of something desirable, is this true? I do not have money, hence I want money. If I have money, I do not want money although I may want more money. As Thomas Hobbes says, you want what you do not have, what you have you love. ${ }^{6}$ This tradition is based on Plato in The Republic and it still seems to survive for instance in the theories of Jacques Lacan: "The term 'lack' is always related, in Lacan's teaching to desire. It is lack which causes desire to arise." ${ }^{7}$ However, this is a mistake, in the following sense. To understand desire, the main term is desirability in the sense that you desire what is desirable. Some things are generally and continuously desirable, like power, love, and money. I want what is desirable; why would I want it only if I lack it? My main point is that desire entails a change of worlds from this actual world into something better, or a possible world that actualizes desirable qualities. Any desire aims at a better world that typically is similar to the actual world except for its additional, desirable features. In this sense, desire always aims at something more, so to speak, but this does not entail any lack in the actual world. However good the conditions in the actual world are, they can be better and then you have a good reason to desire accordingly. They cannot be better in terms of non-increasing values, of course, if you possess the

6 T. Hobbes, Leviathan, 1651, Part 1, Ch 6, Love and Hate.

7 D. Evans, An Introductory Dictionary of Lacanian Psychoanalysis. London: Routledge, 1966, p. 95 . 
maximum. Anyhow, this is irrelevant because you cannot desire what you cannot get. You cannot get an increase of a non-increasing value. In the same way, you cannot desire what you already have.

The lack-theory is a theory of desire that says nothing of desirability considerations. Yet, they explain our reasons for desiring. Now, do we need a motivational theory like the lack-theory? I do not think so. I desire something on the condition that I can see and understand - or imagine - a better possible world in terms of its desirable features. This is enough both to motivate and justify a desire. This decision eliminates a traditional source of frustration. The point is that lack is bad and a failed attempt to correct the situation is frustrating. If all desiring entails a lack and we know that the lack remains regardless of our efforts, desire itself is a frustrating proposition. Anyone who desires will learn this fact. In this sense one must associate desire with suffering, that is, the starting point of desire is always lacking and in this sense bad. Some desires are like that but not all. Notice that desire always aims at a better possible world but the starting point may be categorically bad. Sometimes it is good, although it could be better. If it could not, one cannot desire.

Next, an additional distinction is needed, the distinction between occurring and potential desire. This may somehow relate to unconscious or subconscious desires, but I cannot go into the details of this old and deep problem here. ${ }^{8}$ Now, a rather strange and certainly difficult problem is, when exactly do I occurrently desire something? Perhaps we must postulate something like an opening, invitation, or opportunity for desiring in the sense that I find something desirable and also I see an actual opportunity to imagine the relevant possible world, and then the relevant desire occurs. Notice I am not talking about action except in the metonymic sense of mental action. Therefore, the opportunity does not entail a chance of acting in any behavioural sense. It only means an opening for a thought of the better world that then makes it possible for an actual desire to emerge. I want a new car. Most of the time this is a potential desire, but when I actually see a nice new car this provides me an opportunity or invitation to desire a new car in the occurring sense. In this way, an occurring desire entails a thought of a better possible world that I happen to entertain just here and now. This possible world has its desirable features and I happen to have an opening to think about it. Desire is like a belief. I believe that $2+2=4$ but I do not think about it all the time. When I think of it, I epistemically assent to $2+2=4$. This means that belief is different from belief plus

8 See H.F. Ellenberger, The Discovery of the Unconscious. New York: Harper, 1970; and T. Pataki, Wish-fulfilment in Philosophy and Psychoanalysis. London: Routledge, 2014. 
actual assent. In case of desire, I as if succumb to a desire, say, to possess a new car. Desire may be a mental state or an episode.

To complicate matters, I must put some restrictions on my desires - and at this point some anxious feelings will return. When I want something, I may formulate the object in general terms. I would like to love somebody. I want a new car. I may as well put the object in specific terms. I want the classic Ferrari I saw today in front of my house. I want to marry Ms/Mr X (add you favourite name). What happens here? The basic axiom is: I want the best and I want everything that is desirable. As such my desires know no limits. They are megalomaniac and absolutely immodest. Why this is so? The answer is simple: why would they not be immodest? If you want love or sex, why would you not want the best quality in maximal degree? You first evaluate the matter, you decide what is best, and then you want a maximal amount of it. If you want some good of course you want it all; I find this to be an obvious assumption. Next, I must recognize my limited powers in the real world. This happens because I want to reduce the risks and control my anxiety level, and we all have learned how to do so. We learn it early in life, actually at the same time when our first desires emerge. We will learn that potential desires are free but occurring desires requite control and various types of negative amendment. This brings about anxiety: I potentially desire max-X when I now need to reduce such an unrealistic desire to a realistic $\mathrm{X}$. The tension between max-X and $\mathrm{X}$ is obvious and its case is disappointment and frustration. I always wanted a Ferrari but I drive a Fiat Punto. What you ideally desire and what you can get are two radically different things. Of course, a perfectly adjusted and realistic person learns to forget her maximal potential desires. It may happen that she is so modest that she only wants what she can get, or paradoxically, what she already has. Most of us also want what we cannot get. The worst case scenario is of course that where the person's occurring desires are or tend to be unrealistically immodest or maximal. This person must be unhappy.

To want too much will bring about frustration. If I desire too little, I will suffer in another way. The trick is to find the balance between too much and too little. Too much means either self-deception as to success or instant frustration. Too little means, figuratively speaking, a life of starvation, which at some point will come evident and cause suffering. It entails a life not lived. Too much modesty is a curse in the long run. This dilemma applies to everybody regardless of however powerful they may be. Perhaps some of us can dream of and desire much bigger things than I ever can manage without feeling the pangs of frustration. I cannot desire big things although I can day-dream of them and find my occasional happiness via wish-fulfilment. Desires are different, they must have a touch of realism in them in the sense that the better world must 
somehow be possible when it is seen from my personal point of view. I would say, I can imagine a path that actually takes me from this actual world to the desirable possible world. Of course the path is missing if the possible world is the same as the actual world or if the possible world is internally inconsistent or impossible. However, we can say that the path is also missing if it is too difficult or, in other words, if the possible world is too far away from the actual world. If I say I desire a bigger yacht than any of the Russian oligarchs ever had, I do not think this qualifies as a full-fledged desire in the sense we are discussing here. The path to that possible world is too difficult for me or, in other worlds, it is too far from my actual world.

Obviously, we have a problem here. First, I said that desires are basically unlimited in quality and scope but now I say all desires are a priori limited by our path-related distance considerations between possible worlds. What I want to say is that desires are not day-dreams, empty wishes, or vain hopes; they are something more concrete as they entail the said path between the two worlds. Nevertheless, all desires are as unlimited as possible and in this sense they are immodest. I want as much as possible and perhaps a little more so that my desire flirts with vain hope and wish-fulfilment - and there I must stop. My desires are initially limited only by my realization that they are impossible, unfeasible, or perhaps silly. The basic idea here is as follows. In the case of potential desire I imagine a path to the better, desired possible world but the description of this path need not be realistic. In the case of an occurring desire the path should be at least minimally realistic or something that may take you to a better possible world. I want to be rich, which potentially means I want to multibillionaire, why would I not? I can imagine how this might happen but certainly not in any realistic sense. In daydreaming and wishful thinking the path does not figure at all. I as if jump directly to the ideal state of affairs. I quickly learn that such desires are a waste of time. If I play state lottery, I know the path to riches and I can even calculate the probability of my success. Yet, I should realize that money will not come to my direction.

When I want love I want a beautiful, rich, and young person who is desired by everybody - but this sounds silly. This cannot be a realistic occurring desire because it has no specified object and I am not that desirable myself, as I know painfully well. This is the first step towards anxiety via frustration. The lesson to learn is that I must restrict my desires in two ways, or to make their objects more concrete and less lofty. Therefore, when I say I want to marry Ms $\mathrm{X}$ and I want this individual Ford car I am fine. I did my homework and thus I now know what I can and should desire in the sense that my desires have some relevance to my life and its projects and programs. All realistic desires are restricted in this way although some other desires still may be more or less 
outlandish and hopeless. I may desire something that is not within my range, considering my personal power, because the main thing is that the object is somehow relevant to my life, or the object is in my ball-park.

Concerning frustration, it may not be my main worry here. I may feel no frustration if I am a mature and well-educated person. I am happy with my restricted occurring desires so that I do not bother with my potential whimsies, as I see them. Yet, we can argue that only the total lack of desire may provide peace of mind without a trace of anxiety. ${ }^{9}$ This is to say that even the best adapted desires may be anxious, why? The explanation is that controlling one's desires requires mental effort and moral work. Many desires are depended on a push factor, or they are brought about by emotive and conative drives that are not cognitively controlled, for instance, hunger and sexual urges. A normal person cannot ignore these even if one is properly trained to control them when they emerge. They are a constant source of mental effort or even struggle and therefore prone to bring about anxiety. It is hard to work against them. Heraclitus says, it is hard to struggle against your desire that wants everything and buys it by the price of your soul..$^{10}$ However, also frustration pays its part here: it is disappointing to notice how vulnerable one is and how hopeless the struggle against unacceptable desires can be. Finally, obsession and addiction make life really painful.

Some people desire a lot, some people desire very little, always depending on their personality, life history, and their sense of personal power. If you desire and hope to get too much you will be disappointed, frustrated, and anxious, so you learn to balance immodest desires in relation to life's modest realities, always depending on how much anxiety you are able to tolerate in your life. In our liberal commercial culture people might be happier if they did not desire so much, yet we are constantly pushed to desire even more. Air travel is a good example: in coach you want a business class seat that you know you could but should not buy; you may not want to fly first class because you say it does not add anything desirable to the experience - deep down you know you are deceiving yourself and that entails bad faith. Studies show that that air travellers in coach are bitter and anxious when they see business class cabins and passengers; they come to think of what their own life is like during the twelve hours ahead. Desire management is a battle to stay within some reasonable limits and yet retain the imaginary pleasures of that little extra provided by the

9 A relevant story is told by G. Agamben, The Highest Poverty: Monastic Rules and Form-ofLife. Tr. A. Kotsko. Stanford: Stanford University Press, 2013. The point is, if you follow the rules without thinking it and regard them as all that matters, you are free from desire.

See nı. 
desirable thing, in this case the flight itself. Too little means your inner life is bland and boring, too much means you are always disappointed and anxious. Is a balance possible? Actually, when people are asked they tend to say their life is good as it is and they do not desire anything special. They say the smallest good things make them happiest. In Finland, at least 82 percent of people report, when asked, happiness or great happiness. ${ }^{11}$ They refuse to desire big things, which is too risky and thus frustrating. Life is good as it is, whatever it is like - this what the relevant mental self-defence mechanisms do to you.

\section{Zero Desires}

In the literature on desire and desiring, I think I can detect a definite tendency towards positive and action related examples. I say I want a new car or I want to buy a new car, where a new car is the intentional object. I know I can afford to buy a car, or I can go and buy it; hence, the relevant action is in the books, so to say. Desire does not entail action, however, or even motivation but this is a difficult thing to remember when we think of desiring. ${ }^{12}$ But we can find novel examples once we focus on what I call here zero desires. They have some interesting properties that are relevant to frustration and anxiety. I mean cases like, "I never want to see him again," which is a restriction on a general desire like, "I never want to see any unpleasant people around me," which as such clearly is an unrealizable desire that comes very close to a vain hope and empty wish. Even the word "never" sounds like too much to desire for. Hence, the properly restricted desire is, "I do not want to see him again," at the same time believing that this may still happen.

Zero desires (z-desires) are common. What are their desirability conditions like? In the example above, I want a possible world where he does not appear, so that his absence is what is desirable. In such cases what is desirable is the absence of something so that a desirable world is that which you can travel through without finding this person. Here the object of desire is the lack of something, like the world without poverty and gratuitous violence. Notice that z-desires have no object in the same sense as other desires have. This is a good

11 This figure is based on several studies, but what they show is unclear. Why do researchers jump from "They say they are happy" to "They are happy"? For instance, if go per cent of all people are happy, why do the medical experts say mental depression is a major medical problem in Finland; see (https://www.mielenterveysseura.fi/en/home/mental-health/ mental-disorders/depression).

12 I want a high grade from an exam. After the test I desire and hope for the best. Notice the ambiguity here: before the test my desire entails action but after the test it does not. 
reason, perhaps, to stop talking about an object of desire, or objects of desire in a non-contextual sense. "I want an apple," seems to focus on an apple whose arrival will satisfy the desire and that is all. However, in order to understand any desire we must contextualize its object in the sense that now we focus on the accessible possible world where we find the apple. This is to say that we never want an apple as such. Such an intuition fits well the case of z-desires: their object is a desirable world, namely, any world where the key repulsive fact is missing. I prima facie want any of these worlds. Of course, we also could say that the desirable thing is a negative fact like, "not seeing this person." I may say I am satisfied and happy as long as I do not see this person, when the negative and desirable fact is, "not seeing this person for a long time, possible never." This looks like a narrative or an interrelated chain of facts and hence it may be a good idea to place it in a context in a new possible world. Then it is easier to specify what the desirable state of affairs really is: it is the world where he stays away from my field of perception and perhaps also from social neighbourhood so that there is no chance of meeting him. This sounds like a good idea, namely, to tell the whole story and not to say simply that the person is currently unseen. In this way, it also seems better to talk about a possible world without such a repulsive object and say that this world is desirable.

What then makes z-desires so frustrating? The fact is that z-desires are not satisfiable in the same way as other desires whose object looks so much simpler. I get an apple, a new car, or passionate love, if I do the right thing or (inclusive or) I get lucky. Sometimes things turn out as I hope, I know that, and so it is not irrational to desire those things. Such objects can be ambiguous, metonymic, metaphoric, fuzzy, undefined, too general, etc. but they will still retain their connection to positive facts. One may notice that no desired objects exist but the truth is that we at least have some signposts for tracking the ways the objects tend to move. If I want a car, the linguistic idiom does not tell too much but at least I know in what direction I should look when I am dealing with this desired object. It has something to do with cars or some other things that are somehow related to cars, perhaps figuratively, but anyway. Perhaps I want my manhood back but when we analyse this we can and must start with fine cars.

Now we should ask, are z-desires unique and more problematic than other desires? I argue that they indeed are because they do not have an object in the same sense as other desires do. Let us first notice the following ambiguity: "I never want to see you again" may mean "Stay away from my field of vision," so that the relevant object is the fact that this person indeed stays away from my field of vision. But the same sentence may as well mean that I want to live in that kind of the world where I may have nothing to do with him. This is an example of the expansive nature of desires, or of their inherent limitlessness. 
What starts as a simple fact concerning the contents of my field of vision expands, when we consider it more closely, towards the idea that you totally disappear from my life. Then, because I must somehow limit this, I arrive at some middle ground position concerning your visibility in my life. Whatever this final position is it concerns the whole, or at least of a considerable slice, of a good possible world.

Now, a crucial asymmetry between positive and negative objects of desire exists, namely the second object cannot be satisfied in the same way the first one can. Compare, "I want to see you," and "I do not want to see you." In the positive case, every time I see you I feel good about the event - my desire is satisfied. In the second, everything is different: Every time I do not see you, I feel good - my desire is satisfied. This is nonsense, of course. When I do not see you I feel nothing. If I see you I feel bad because my desire is frustrated and I am anxious as long as I anticipate this. This happens because I might see you. Nothing guarantees that I do not see you, so I am always afraid of it, or at least I stay uneasy. I must anticipate disappointment and this entails anxiety. Therefore, z-desires are a source of continuous anxiety, perhaps it is mild and more or less hidden but it still lingers on. In the case of z-desire I can anticipate nothing but anxiety. The only way to feel satisfied about a z-desire is when you get some definite guarantees that the repulsive fact will not occur. If you do not want to see Bill you may desire that Bill is dead. But this sounds like a potential and immodest desire that you aim not to recognize. Bill's demise is possible, of course; however, this is a novel fact that was not part of the original z-desire narrative concerning its desirable possible world. It is another expansion of the original z-desire. Think of it: "I do not want to see him ever again" is not the same as "I want to have guarantees to the effect that I will not see him ever again." These are two different desires. Moreover, the latter one concerning guarantees happens to be a positive desire: "I want guarantees ..." To conclude: z-desires promise us no happiness through satisfaction; on the contrary, they promise us frustration through failure. The only positive aspect of $\mathrm{z}$-desire is this. I do not want to see him ever again and I am anxious that I will see him. In some special cases I believe that the situation is particularly dangerous but he does not appear. I feel relieved and in this sense happy. But this is a special case.

One can make z-desires feel good as if they were satisfied. Here we can use the same strategy we used in the case of non-increasing value. The strategy was this simple: when you have the full count of the value you cannot get more and it all starts feeling unimportant, but you can recover your sense of value by imagining the loss of the value in question, or you may risk the value if you need a more concrete reminder. For a while your appreciation of the value 
will return although it will not last. We can play the same game with z-desires: Imagine that the repulsive thing will appear or somehow risk the value and then you can feel the satisfaction. Remind yourself how good things are now when the repulsive possible world has not materialized and think of how bad it would feel if it did. You simply tell yourself that Bill is here and when he is not, you feel good. All this helps you keep conscious of the good thing, which feels good, although it does not change the basic truth, namely, you are battling your frustration and anxiety. Z-desires keep the good thing valueless and as such non-desirable unless compared to its repulsive alternative, which itself is less than ideal thing to do. To constantly remind yourself of what is a repulsive possibility is in itself a source of anxiety. Therefore, you cannot avoid anxiety, regardless what you do. When the bad thing stays away, the situation may stay indifferent to you but, of course, when the bad thing emerges you are unhappy; the threat exists so that when you expect bad thing emerge you are anxious; the only way to feel happy is the counterfactual strategy of imagining the emergence of the bad thing while it stays away; but to imagine a bad thing is in itself anxious. We are in trouble with our z-desires, which is based on the idea of the desirability of the absence of repulsive things. The situation is a good example of the Catch-22.

\section{Desire as a Metonym}

Here I follow Lacan, who says desire is a metonym. ${ }^{13}$ We say de dicto "I want that the world is without war" and de re "I want the world that is without war." In the first case, if the world goes to war I do not want it any longer. In the second case, I may still desire it. In the first case, the lack of war is essential, in the second case it is not. De re you got what you wanted, a world that happens to be without war, and thus it does not matter if war breaks out later. In the case of de dicto interpretation of a desire the problem is my inability to spell out the exact meaning of desiderata. This is to say that I myself may not know what I want or what the intentional object of my desire is. Yet, most of the time we think the contrary to be true, and thus we refuse to see any problem. If you want to be a good father, what do you want? It is hard to say. What about "All my life I wanted to be as free as possible"? The de dicto interpretation focuses on the meaning of the desired proposition making it vulnerable to all the problems that stem from the semantics and pragmatics of language. For instance, it

13 Evans, 1996, pp. 38, 113f; and A. Lemaire, Jacques Lacan. Tr. D. Macey. London: Routledge, 1970, pp. 195f. 
is hard to believe that someone really wanted to be a sadistic monster, even if he says so, simply because such a self-ascription is socially so inadmissible, except if it is pronounced ironically or it implies pathological self-hatred. Nevertheless, "I want to be a sadistic monster" is a perfectly good desire description. A de dicto desire may surprise me and hence also frustrate me. I say to myself, anxiously, "I really did not want that." Let me bypass these problems and move over to the world of de re desires.

De re cases focus on the intentional objects of desire, when an object displays one single package of intentionality and desirability. Ice cream is sometimes an object one can appreciate by ascribing desirability and intentionality to it. It is good and I myself (de se) aim at it. In this way, ice cream as an object is the object I think of and aim at on the basis of its desirable characteristics. What can go wrong with de re interpretations of desire? I may not exaggerate too much if I say, everything.

Suppose I know what I want when I say, "I want a car that is red." However, I do not know that red paint fades significantly quicker than any other colour. If I knew it, I would be deeply troubled by the fact. In other words, I would be frustrated because now I must reconsider my preference for the colour red. According to another interpretation, I did not get what I really wanted. Another anxious choice is now facing me - I do not like it, namely, to keep the car or not. I want to marry a beautiful person but I should realize that with him or her comes an ugly family. All de re desires seem tainted in the sense that along with the good thing comes a bundle of bad things. Of course you may say you got more of the good thing than you ever wanted but then you must forget the other side of things. Moreover, at de re level we lose contact with desirability conditions. That the car colour is nice and fades quickly does not say anything of why I wanted it: they just happen to be properties of the car.

No desirability considerations occur in a vacuum, even if one may try in good faith. Typically, people think that their de dicto desires are motivated on the basis of some truncated account of them, especially when the object is rich in tempting features. I want her so much that I am unable to focus on the total package formed by all the relevant features of it (de re). The problem is, of course, that a simple object comes de re with a big baggage of other things, some of which not so attractive, some even repulsive. The basic rule is, when you have your object and possess it, you get many occasional or irrelevant things as well. Moreover, the evaluation of these extras should be independent of the desirability characteristics of the object itself. Often it is not so, which indicates a certain degree of irrational reasoning.

Psychologically speaking, we tend to desire something independently of the evaluation of its extra baggage. Is this irrational? I want a red car but now I 
am told about the red colour. I may regret it but I still want it. I want a shot of whisky and I am told that it may be, in my current medical condition, a dangerous idea. I still want whisky although I regret that I should not have it. In this way, the extra features of my de re desire may not influence the desire itself but my decision to act on it, or the object's acceptance is in danger. Suppose I have paedophilic desires. I am fully aware that I should not entertain them because they are sick and shameful. I also know that such desires are dangerous but this is an actionist worry. Yet, my moral reservations may not suffocate my desire.

I call this phenomenon the independence interpretation of desired objects. When I fix my de dicto interpretation of the object, or I think I know what I want, I also am committed to it. When I consider the de re interpretation of the same desire I follow the principle of the priority of de dicto over de re, in the sense that the extra features of de re object do not matter - I desire the object regardless of them, or even regardless of any of its features. Of course, one may suggest that my de dicto desired object is originally formulated and accepted as desirable on the basis of my considered opinion of the de re object. For instance, I research the properties of red cars and learn about the fading of the colour. I still desire a red car and that means I do not mind the fading. This seems to be so in some cases, but not generally or as we may say, only partially. I may consider some of the extra features de re but only some and then fleetingly. The proof of this point is indirect. As I said above, our de dicto desires tend to be resistant to the introduction of repulsive de re considerations. I may have a hard time getting rid of some of my desires I know I should not have just by reminding myself of their intrinsic problems. Desires track their satisfaction persistently and even stubbornly, that is, a desire tends to be immune to criticism and counter-evidence. This may not be irrational because it only proves, as I said, that desires track their satisfaction. All this indicates that our de dicto desires are formed independently of a full evaluation of their full de re package. This is one reason why desires are, in the end, anxious: I should pay more attention to the de re side of desire, or I should not give de dicto such priority. The battle is between dreams and reality. I give an example of de re vs. de dicto. When a man (women are stronger) buys a new car, the sales person calls him a couple of weeks later just to see how he now feels about the car. This is important because at this time reality has hit and his dreams may be frustrated. He may be suffering from post-purchase blues. The best of all desires tend to be the most vulnerable.

All this makes desire frustrating, anxious, and even scary, so to speak. We instinctively know it is not a good idea to give a free range to our imagination concerning de dicto desiderata. The nature of frustration brought about by desire is, therefore, twofold: it is frustrating that desires are so stubborn, or hard 
to extinguish, and in many cases the extra baggage that comes along with the de re object is something one finds too repulsive for comfort. I may have fixed my de dicto object without paying due attention to the problems at the de re level, or what I will get. It also seems that when I fix the object as something I actually desire this mental act does not allow for a realistic evaluation of the relevant extra features. Let me explain: I say I want to marry this beautiful person and I remind myself of the ugly family but I say I do not care. Epistemically speaking, I should consider the whole set of relevant properties of the case but I am unable to do that. When I focus on beauty I leave other relevant consideration aside as if they did not exist. If I am lucky enough to realize my desire or move to the new and better possible world, I am bound to notice that this world contains features that I do not want or even features that I find impossible to tolerate. Sometimes they come as a surprise, sometimes not. I may have known about them but, because of my desire, I did not form a realistic picture of them. The rule is, beliefs must remain independent of desire. Your desires depend on your beliefs but not the other way round.

Once I realize how risky desires are I cannot avoid of being anxious of them. I try to stay away from such desires, that is, desires may be dangerous. I do not want to expose myself to certain kind of desirability considerations. One way is to restrict your diet of commercial information and persuasion. Of course, nothing you do may eliminate all anxiety because it is embedded in the nature of desire. Whatever you desire ultimately disappoints you. Jacques Lacan says desire is a metonym in the sense that what you want and what you get are never the same but at least they are metonyms, that is, somehow related to each other at the linguistic level. ${ }^{14}$ You want a horse and then you get this horse, so at the level of horsehood all is well but nothing guarantees your personal gratification. On the contrary, de re the horse is never the horse you wanted de dicto. Lacan's point is, what you wanted, an idealization, is related to what is, or the real thing, only metonymically. In this sense, you got what you got when you wanted a beautiful horse, and these two still form a metonymic pair. Actually, you can form as many such metonymic pairs as you like and then wonder if you got what you really wanted. What you want and what you get form a set of metonymic pairs. Given that you wanted a horse, what you get can be characterized in so many different ways. How to certify that de dicto

14 But for Lacan at least this does not mean that desire can be simply reduced to the idea of yearning or pining for something lost. Desire for him is always a desire for something else, because it is caught in what he calls "the rails of metonymy." (www.lacanonline. com/2010/05/what-does-lacan-say-about-desire/). Also, Evans, 1966, pp. 36ff., 116; and D. Leader, Why Do Women Write More Letters than They Post? A Meditation of the Loneliness of Sexes. London: Faber \& Faber, 1996, pp. 118-110. 
and de re interpretations still concern one given desire? They need not share a concept, that much is certain, like "horse" and a "bag of bones." Or what to say about the highly ambiguous Biblical metaphor, you want to give "no pearls to the swine"? It seems you need to start from de dicto desire and trace its effects all the way to the real world. If the de dicto object can be traced back to reality we have one given desire. Think of this example: de dicto I want to be a good father and de re what one gets is a sadistic monster. The key problem must be that de dicto and de re depend on different types of intentional interpretation. De re comes close to being an extensional context while de dicto pics a superintensional one. The former recognizes all properties of the object unlike the second which is dependent on what is included in the intentional object. You do not want to look at what you actually got in life, it is far too risky. 